\title{
Esse vírus de science fiction: doença e alteridade em Caio Fernando Abreu
}

Milena Mulatti Magri ${ }^{1}$

Acho que, às vezes, a literatura precisa de vacina. Às vezes você inocula no corpo da escrita o veneno, o mal. É uma perversão, mas esse é que é o sal da literatura. Literatura não é "normatividade". Às vezes se pode mostrar a deformidade.

João Gilberto Noll

O fragmento selecionado como epígrafe, reproduzido acima, foi retirado de uma entrevista concedida por João Gilberto Noll em 2007, para a jornalista Gisela Anauate Bergonzoni, e recentemente publicada, tardiamente, na revista Peixe Elétrico, em razão da lamentável morte do escritor. No contexto da entrevista, Noll se refere a seus personagens que são, simultaneamente, opressores e oprimidos, reivindicando, dessa forma, o direito de a literatura tudo poder dizer. Para o escritor, a literatura não pode se esquivar de falar sobre o doente, o mal e o disforme. Mas e quando a doença e a deformidade não são metáforas? E quando o escritor se expõe, em sua literatura, para dizer que "é no corpo que escrever me dói agora"? Esta frase, retirada de uma das crônicas de Caio Fernando Abreu, publicada em 1994, ensaiava uma forma de como o autor tornaria público o diagnóstico de aids, recentemente confirmado, à época.

Os limites éticos implicados na utilização de uma metáfora para tratar do tema da doença foram inicialmente discutidos em dois ensaios fundamentais de Susan Sontag - "A doença e suas metáforas" e "A aids e suas metáforas". Para a autora, o uso de metáforas que abordam a doença comporta, em geral, um sentido pejorativo que afeta de modo direto ou indireto aquele que padece de um mal que não pôde escolher. Sontag justifica seu ponto de vista a respeito do assunto a partir de sua experiência pessoal. Ainda nos anos 1970, a escritora precisou se submeter a um tratamento de um câncer de mama agressivo, com poucas chances de cura. Nesse período delicado de sua vida, Sontag se

\footnotetext{
${ }^{1}$ Doutora em letras e pós-doutoranda na Universidade Estadual Paulista Júlio de Mesquita Filho (Unesp), São José do Rio Preto, SP, Brasil. Bolsista Fapesp. Corcid.org/0000-0002-8034-4211. Email: milenamagri@yahoo.com.br
} 
deparou inúmeras vezes com metáforas - sobretudo metáforas que evocavam um campo semântico ligado às forças armadas - que apontavam a doença como um invasor que deveria ser eliminado. De acordo com a perspectiva da autora, esse tipo de metáfora acerca das mais variadas doenças, e especialmente recorrentes na abordagem do câncer, provocava um sentimento de autodepreciação e, por vezes, sugeria que o paciente era, em alguma medida, responsável pelo sofrimento que abatia seu próprio corpo. Ela cita como exemplo as frequentes associações entre o paciente de câncer e a depressão, como se a tristeza acumulada durante toda a vida fosse a causa da doença. Logo, o paciente de câncer passa a ser visto como uma pessoa que se permitiu adoecer porque nunca adotou uma postura positiva a respeito da própria vida. Segundo Sontag:

A metáfora dá forma à visão de uma doença particularmente temida como um "outro" alienígena, tal como o inimigo é encarado nas guerras modernas; e a transformação da doença em inimigo leva inevitavelmente à atribuição de culpa ao paciente, muito embora ele continue sendo encarado como vítima (Sontag, 2007, p. 85-86).

Em seu primeiro ensaio, Susan Sontag se concentra nas metáforas do câncer e também de outras doenças cujas imagens são recorrentes na literatura, como a tuberculose, a qual se acreditava que acometia especialmente pessoas sensíveis e criativas. No entanto, a autora será impelida a retomar o tema da doença, no final da década de 1980, em razão do surgimento de uma enfermidade que atemorizava a população por inúmeros fatores, tanto por razões clínicas quanto sociais. A divulgação dos primeiros casos de aids, ainda no início daquela década, estava fortemente associada a um grupo minoritário em específico, a saber, homens homossexuais. Além disso, essa doença nova, que desafiava os limites da medicina moderna, aparecia justamente em um momento em que ainda eram recentes algumas conquistas no campo da sexualidade, inclusive no que diz respeito ao questionamento da heteronormatividade instituída. Tais avanços nos campos da cultura e do comportamento foram alcançados, em grande parte, por meio dos movimentos de contracultura e das lutas pelos direitos de minorias, que vinham sendo cada vez mais reforçados desde o fim da década de 1960 e intensificados nos anos 1970. A confirmação dos primeiros casos de aids em pacientes homossexuais 
provocou um retrocesso e manifestações de intolerância em relação a determinados grupos sociais que passaram a ser imediatamente associados como doentes em potencial, promovendo dessa forma uma estigmatização não só sobre a doença mas também sobre determinados comportamentos, por meio da identificação dos então chamados "grupos de risco". Esse procedimento de exclusão social era fomentado pelo medo de uma contaminação generalizada, uma epidemia incontrolável:

A ideia de que a AIDS vem castigar comportamentos divergentes e a de que ela ameaça os inocentes não se contradizem em absoluto. Tal é o poder, a eficácia extraordinária da metáfora da peste: ela permite que uma doença seja encarada ao mesmo tempo como um castigo merecido por um grupo de "outros" vulneráveis e como uma doença que potencialmente ameaça a todos (Sontag, 2007, p. 127).

A estigmatização dos grupos sociais, sobretudo os homossexuais, por vezes gerava ainda maiores dificuldades e constrangimentos para o paciente detectado com o vírus HIV. O diagnóstico da contaminação era acompanhado da revelação de um aspecto fundamental da identidade do paciente, que passava, então, a ser identificado como um "outro" temível socialmente. O artigo "A aids como construção social", publicado por Andrea Giovannetti e Iolanda Évora, na Revista USP, em um dossiê especial sobre aids, é revelador de como o estigma e a exclusão social, aos quais o paciente de HIV/aids é submetido, apresentam-se como um fardo ainda maior que a própria doença. As pesquisadoras recolheram depoimentos de pacientes cujos diagnósticos confirmavam a detecção do vírus, embora nem todos já tivessem manifestado a doença. Segundo as pesquisadoras, "a condição de portadores dessas pessoas, ainda que referência costumeira de suas falas, não se impunha como faceta prevalecente da subjetividade de cada um" (Giovannetti e Évora, 1997, p. 128). O que sobressaía em seus depoimentos era o processo social de exclusão e estigmatização no qual se incluía, para muitos, a inevitabilidade da divulgação de sua orientação sexual:

O fardo físico, por exemplo, de serem portadores de HIV era muito pouco privilegiado como tema das falas dos entrevistados, em que pese que em nenhum deles a síndrome se manifestara em seus rigores. Aquilo de que todos queriam falar era do fardo social: do estigma, da segregação, da falta de amparo governamental, da solidão que os obrigava a transformarem-se em "aidéticos" a despeito de si mesmos (Giovannetti e Évora, 1997, p. 129). 
A relação entre aids e homossexualidade já estará presente na obra de Caio Fernando Abreu no início da década de 1980. Sua novela "Pela noite" (Abreu, 2007), que integra o livro Triângulo das águas, publicado em 1983, será um dos primeiros textos ficcionais a abordar o tema na literatura brasileira. Nele, dois rapazes se encontram num sábado à noite e dividem seus desejos e angústias pessoais ligadas à sua homossexualidade e, inevitavelmente, ao medo diante da confirmação dos primeiros casos de aids. Os personagens, que adotam os nomes fictícios de Pérsio e Santiago, são na verdade colegas de infância, quando viviam em uma cidade do interior, acentuadamente caracterizada pelos personagens como tradicionalista e preconceituosa. Anos mais tarde, eles se reconhecem, casualmente, em uma casa de encontros homossexuais, em São Paulo, cidade onde passaram a viver. A partir desse reencontro inesperado, eles combinam um novo encontro, no qual dividem suas histórias e compartilham suas angústias diante de uma vida solitária.

Os personagens apresentam personalidades antípodas. Pérsio se caracteriza como um personagem eufórico, excessivamente falante. Ele rememora seus traumas de infância por ser estigmatizado como homossexual e transfere para a sua própria vivência pessoal os impactos dessa opressão que sofrera. A vivência de sua sexualidade comporta um sentimento ambíguo, de prazer e culpa. Pérsio sente dificuldade de se apegar às pessoas com quem se envolve e de se entregar a um relacionamento duradouro. Devido à sua preferência por encontros furtivos e numerosos, ele se sente amedrontado diante do anúncio dos casos de aids entre homossexuais. Santiago, por sua vez, apresenta um temperamento menos eufórico, em que o personagem quase não se expõe. Diferentemente da experiência de Pérsio, Santiago viveu um relacionamento longo, de dez anos, com um grande amor que conheceu na universidade. Ele e seu namorado, Beto, descobriram e vivenciaram sua homossexualidade sem culpa, desfrutando de um relacionamento caracterizado pelo amor e pela cumplicidade. As diferentes perspectivas dos personagens a respeito de uma relação amorosa e homossexual instauram uma reflexão a respeito da alteridade, no texto. Para Pérsio, a relação com o outro é sempre marcada por uma tensão que sugere, por fim, uma dificuldade na aceitação de uma alteridade que reside em si mesmo. Este conflito interno do personagem pode ser observado a partir de suas próprias palavras: 
Entre dois homens, amor é igual a sexo que é igual a cu que é igual a merda. Sabe que não aguento merda? Eu vejo um cara e gosto e tal e me aproximo e rola umas, sempre rola umas, porque eu canto bem, eu sei cantar, veja que vaidade, e daí eu penso Deus, daqui a pouco a gente vai pra cama e chupa daqui, chupa dali, baba, roça, morde, e no fim inevitável tem o cu e a merda no meio (Abreu, 2007, p. 175).

A dificuldade do personagem em sua relação com a alteridade acaba por se revelar um limite que Pérsio vivencia no próprio corpo. O prazer sexual acaba se convertendo em repulsa e esse paradoxo se manifesta tanto na relação com o outro com quem se envolve quanto em relação a um "outro" que habita em si mesmo, cujos desejos são incongruentes em relação ao que Pérsio espera ser uma fonte de satisfação. Os corpos masculinos, iguais, sugerem uma relação de espelhamento por meio da qual tudo o que Pérsio sente em relação ao outro com quem se relaciona é também, por identificação, a manifestação daquilo que ele sente em relação a si mesmo. Há uma incongruência na sua forma de se relacionar com a alteridade, tanto no que diz respeito ao outro com quem se envolve quanto com o "outro" estigmatizado socialmente e que é constitutivo de sua própria experiência. Já a perspectiva de Santigo em relação à experiência amorosa e homossexual será o oposto do que Pérsio nos apresenta. Para Santiago, o amor é uma relação de complementariedade que só se concretiza na aceitação e completo acolhimento do outro, seja o "outro" com quem se relaciona, seja o "outro" que faz parte se sua própria constituição subjetiva:

E se tudo isso que você acha nojento for exatamente o que chamam de amor? Quando você chega no mais íntimo. No tão íntimo, mas tão íntimo que de repente a palavra nojo não tem mais sentido. [...] Se tudo isso, se tocar no outro, se não só tolerar e aceitar a merda do outro, mas não dar importância a ela ou até gostar, porque de repente você até pode gostar, sem que isso seja necessariamente uma perversão, se tudo isso for o que chamam de amor. Amor no sentido de intimidade, de conhecimento muito, muito fundo. Da pobreza e também da nobreza do corpo do outro. Do teu próprio corpo que é igual, talvez tragicamente igual (Abreu, 2007, p. 178-179).

Os posicionamentos antípodas dos personagens acabam estabelecendo, também entre si, uma relação de espelhamento, uma vez que cada um deles representa, para o outro, aquilo que falta em si 
mesmo ou, em alguma medida, aquilo que cada um deles rejeita em sua experiência pessoal. Santiago defende o amor e a cumplicidade numa relação homoafetiva não só porque essa foi uma experiência que o fez feliz, mas também porque ele tem dificuldade em admitir que seja possível se relacionar com um outro de forma fortuita, sem se envolver emocionalmente. Nesse sentido, a relação de Santiago com a alteridade pode ser interpretada como uma relação que procura anular aquilo que há de dessemelhante e perturbador.

No entanto, mesmo diante de uma relação homoafetiva plena de cumplicidade e acolhimento, a adversidade não se exclui no horizonte de possibilidades. Diante da defesa incondicional do amor, que Santiago exalta, Pérsio pergunta, enfim, por que seu relacionamento havia acabado. Nesse momento de grande tensão na narrativa, Santiago revela que seu companheiro estava morto. Ainda que seja uma breve passagem, a menção à morte de Beto, antes da revelação de sua verdadeira causa, instaura uma perspectiva de angústia e medo. Sabendo-se que se trata de uma relação homoafetiva, há uma sugestão, que não se confirma, de que Beto teria morrido em decorrência da aids. O medo da contaminação por HIV já havia sido mencionado por Pérsio, o que torna possível que essa hipótese seja levantada pelo leitor. A apreensão em relação a uma possível morte provocada pela aids, rapidamente sugerida pelo texto, revela um traço peculiar do narrador dessa história, que poderia agir de forma cruel com os próprios personagens. Essa falsa expectativa, contudo, é desmentida logo em seguida, quando Santiago revela que Beto havia sido atropelado. Sua morte é descrita como um evento rápido e inesperado, como se Beto nem sequer tivesse tido tempo de sofrer diante da dor e da perspectiva da morte. Essa abordagem da morte de seu companheiro pode ser lida como o oposto do que se entendia, até então, no início da década de 1980, sobre a morte em decorrência do agravamento do quadro do paciente acometido pela aids - uma morte dolorosa e sofrida, tanto pelas complicações físicas que a debilitação provocava, quanto pelo isolamento social e pela angústia diante de uma doença nova, contra a qual pouco ou nada se podia fazer. A revelação da verdadeira causa da morte do companheiro de Santiago aponta para uma espécie de recuo do narrador, como se ele não tivesse tido coragem o suficiente de ser cruel com seus próprios personagens, imputando-lhes uma carga tão alta de sofrimento - agindo, assim, de forma contrária à que João Gilberto Noll diz conduzir o destino de seus próprios personagens, conforme mencionado na epígrafe que abre este texto. 
A presença da aids como sinônimo de medo e angústia não é exclusiva dessa narrativa de Caio Fernando Abreu. O conto "Dama da noite", publicado no livro Os dragões não conhecem o paraíso, no final da mesma década, em 1987, apresenta um diálogo entre dois personagens de gerações diferentes e que, por essa razão, também encaram o envolvimento afetivo e sexual a partir de diferentes perspectivas. Nesse diálogo, a personagem mais velha insiste em falar de seu medo em relação a aids, não só por conta das complicações que a doença trazia, mas, sobretudo, pelas mudanças que isso implicava no estabelecimento de uma relação afetiva e íntima. $O$ envolvimento com outra pessoa deixa de ser uma fonte de prazer para se manifestar como uma fonte de preocupação e, no limite, como uma paranoia:

Você não viu nada, você nem viu o amor. [...] Já nasceu de camisinha em punho, morrendo de medo de pegar aids. Vírus que mata, neguinho, vírus do amor. Deu a bundinha, comeu cuzinho, pronto: paranoia total. Semana seguinte, nasce uma espinha na cara e salve-se quem puder: baixou Emílio Ribas. Caganeira, tosse seca, gânglios generalizados (Abreu, 2010, p. 113).

A aids se confirma como um "outro" temível, que ronda feito um fantasma e atormenta todas as possibilidades de interação eu-outro. Em sua crônica "A mais justa das saias", Caio Fernando Abreu menciona aquilo que para ele seria uma das piores consequências da aids, "a aids psicológica", por meio da qual "iremos todos enlouquecer, se passarmos a ver no outro uma possibilidade de morte" (Abreu, 2006, p. 59). Diante da possibilidade real de contaminação e da estigmatização de grupos sociais, a aids se impõe como uma dificuldade para o estabelecimento de relações interpessoais, transformando o prazer em culpa e a entrega de si a um outro em ameaça.

A confirmação da soropositividade do autor, já na década de 1990, vem acompanhada de um quadro social e cultural ainda muito vinculado aos estigmas e discriminações que marcaram a divulgação dos primeiros casos de HIV/aids, mesmo que alguns índices já apontassem para um novo contexto de propagação da doença. A essa altura, o vírus não estava mais circunscrito a homossexuais e era especialmente crescente o número de mulheres casadas que eram contaminadas pelos próprios maridos. Diferentes meios de comunicação divulgavam campanhas de prevenção e o tema já era debatido publicamente, em diferentes faixas etárias (Buitoni, 1997). Ainda assim, 
o estigma sobre a doença permanecia e afetava de modo direto a vida do soropositivo. Diante da descoberta de seu próprio quadro clínico, depois de ver vários amigos e conhecidos morrerem em decorrência da aids, Caio Fernando Abreu decide tornar público seu estado de saúde, divulgando a confirmação do teste de HIV por meio de suas crônicas publicadas no jornal $O$ Estado de S. Paulo. Ao escolher lidar com o assunto abertamente, o autor não se esquiva de discutir, inclusive, o preconceito da sociedade contra a doença. Nesse sentido, Caio Fernando Abreu reforça uma separação entre "nós" e "eles" ao abordar o tema: "para os outros, esse vírus de science fiction só dá em gente maldita" (Abreu, 2006, p. 113). O inusitado dessa colocação do escritor, no entanto, é que a formulação por ele utilizada dá destaque para o "outro" como sendo as pessoas que não eram capazes de se desvencilhar de seus próprios preconceitos. Essa é uma inversão significativa em relação ao que era propagado pelo senso comum, na época e ainda hoje, uma vez que quem é usualmente tratado como "o outro" é sempre o estigmatizado, nesse caso, o portador do vírus. O procedimento de estigmatização do "outro" - o doente, o diferente, ou o estrangeiro - já é destacado no ensaio de Susan Sontag (2007, p. 115):

[...] há uma ligação entre o imaginário da doença e o imaginário do estrangeiro. Suas raízes se encontram talvez no próprio conceito errado, sempre identificado com o não-nós, o estranho. A pessoa poluente é sempre errada, observou Mary Douglas. O inverso também é verdadeiro: a pessoa considerada errada é vista, ao menos potencialmente, como uma fonte de poluição.

Em decorrência de sua decisão de tornar público seu estado de saúde e de questionar o preconceito ainda atuante contra o portador do vírus, Caio Fernando Abreu dá continuidade ao compartilhamento de seu dia a dia no convívio com a doença, por meio de suas crônicas. São frequentes os relatos de suas febres noturnas entre outros sintomas, acompanhados do seu drama pessoal por ver-se diante da possibilidade da morte. ${ }^{2}$ Nessa mesma época, Caio Fernando Abreu escreve uma peça de teatro, publicada postumamente em seu Teatro completo, em que o autor manifesta muitas de suas angústias vivenciadas desde que os sinais da doença começaram a se manifestar. Trata-se da peça "O homem e a mancha", uma releitura que o

${ }^{2}$ Suas crônicas foram recolhidas e publicadas postumamente no volume Pequenas epifanias (Abreu, 2006). 
escritor faz do romance Don Quijote de la Mancha, de Miguel de Cervantes. Desde seus contos de Os dragões não conhecem o paraíso, a mancha é um índice para tratar da doença, mesmo quando esta não é mencionada diretamente. Isso porque os primeiros casos de aids vinham acompanhados de um tipo raro de câncer de pele, o Sarcoma de Kaposi, que espalhava manchas pela pele. Fernando Arenas destaca a presença dessas manchas na leitura do conto "Linda, uma história horrível" (2010), no qual o protagonista visita sua mãe para dar a notícia de que estava contaminado:

O narrador visita sua mãe e na chegada ele se depara com uma casa em declínio. Na verdade, a casa é uma imagem espelhada do narrador, um homem em seus quarenta anos que tem AIDS, e de sua mãe, mais de vinte e cinco anos mais velha que ele. Ambos carregam traços da doença, do tempo. [...] Em "Linda, uma história horrível", a mãe, o filho, a cachorrinha de estimação, a casa e o país estão todos incluídos em uma decadência. As lesões de KS [Sarcoma de Kaposi] no peito do protagonista refletem as manchas roxas desbotadas do carpete da sala de estar e da cachorra quase cega e senil (Arenas, 1999, p. 15, tradução nossa).

A presença da mancha, tanto no conto quanto na peça, é uma maneira cifrada de se referir à doença. Em "O homem e a mancha", Caio Fernando Abreu recorre ao duplo significado da palavra, pois, num primeiro momento, a "mancha" faz referência ao romance espanhol, remetendo à região em que vivia o protagonista Don Quixote antes de partir em busca de aventuras, inspirado pelas leituras de romances de cavalaria. Há uma polissemia na palavra, no entanto, que se confirma no andamento da peça, uma vez que a "mancha" também faz menção ao câncer de pele que acomete o paciente com aids. A peça é um monólogo, representado por um único ator que se divide em cinco personagens diferentes: Ator, Miguel Quesada, Homem da Mancha, Dom Quixote e Cavaleiro da Triste Figura. O principal conflito do Homem da Mancha é, justamente, encontrar a mancha: "HOMEM (Acorda de repente.) - A mancha, meu Deus, a mancha. Onde foi parar a mancha? Estava aqui, agora mesmo. Não pode ter sumido assim" (Abreu, 2009, p. 227). As imagens da doença e da degradação do corpo estão sempre presentes na fala deste personagem e são associadas à figura reiterada da mancha: "Uma mancha no meio dos meus miolos. Um gânglio, um derrame, um aneurisma. Mas não dói, não pulsa, não sangra [...]. No meu corpo. Na minha pele, como uma tatuagem, uma queimadura" (Abreu, 2009, p. 229). Ele manifesta seu desespero diante dos 
sinais da contaminação e sua perplexidade diante da força da doença, ainda que ela não seja nomeada em nenhum momento:

HOMEM (Olhando a própria pele, horrorizado.) - Ah, não... Na minha própria pele, não. Por piedade, Senhor, poupai-me. Já se foram tantos, já se foram quase todos. Eu devo ser um dos últimos. Eu tenho que resistir. Dai-me forças e dai-me fé, meu Deus. (Benzendose.) Oh, puríssimo anjo Rafael, curador divino das feridas humanas, verte em minhas veias o líquido sagrado de tua ânfora dourada para purificar meu sangue!" (Abreu, 2009, p. 239).

Uma das facetas do protagonista da peça, a personagem de Dom Quixote de Caio Fernando Abreu - aludindo ao Dom Quixote de Cervantes, que é acometido por delírios e pela perda do senso de realidade em razão da leitura dos livros de cavalaria - é justamente aquela que sofre com os delírios provocados pela febre, apresentando a experiência da doença como uma experiência limite. $\mathrm{O}$ delírio se manifesta por meio dos "nigromantes do mal" (Abreu, 2009, p. 228), que tanto o atormentam:

Meia-noite. Preciso estar alerta. Como um raio, um leopardo, uma serpente. Esta é a mais perigosa de todas as horas. Aquela que feiticeiros e nigromantes escolheram para seus nauseabundos batuques. Sabedores que aqui vela em solidão um cavaleiro inimigo do mal, por supuesto hão de vir importunar-me com suas perfídias. [...] Guardai distância de mim, se tendes amor a vossas peles fétidas, lavradas de cascas purulentas (Abreu, 2009, p. 238).

A elaboração de diferentes imagens que remetem à doença, ao malestar, ao delírio são constantes no texto. Essas imagens introduzem o drama particular no escritor, que poderia ser interpretado como mais uma faceta em que se divide o sujeito dessa peça, já representado por meio da fragmentação em cinco personagens diferentes. Esse sujeito multifacetado pode ser compreendido como uma forma de representação da alteridade, que passa a ser constitutiva de um paciente acometido por uma doença grave, como a aids, e que se vê obrigado a lidar com a perspectiva do fim da própria vida. A aids deixa de ser apenas um "outro" temível e alheio para se tornar um "outro" inexorável à vida do próprio sujeito - nesse caso, do próprio escritor.

Uma característica recorrente nesse texto que aponta para uma elaboração formal da fragmentação da subjetividade, como mencionada anteriormente, é a exploração dos vários sentidos de fronteira. Além da representação desse sujeito/personagem 
multifacetado - um personagem habitado por várias fronteiras -, há também uma espécie de hibridismo textual, por meio do qual o autor mistura elementos próprios do teatro e do romance. A peça se divide em Prólogo, 26 Cenas e Epílogo. Cada uma destas partes é precedida por um subtítulo que resume a ação que deverá se desenvolver na cena seguinte, imitando, assim, os subtítulos que davam início a cada um dos capítulos do romance de Cervantes. Desse modo, temos, em Caio Fernando Abreu e em Miguel de Cervantes, comparativamente:

\section{CENA 20}

De como se faz noite e nosso herói arma o camping para o repouso enquanto lembra a bem-amada em suas orações (Abreu, 2009, p. 246).

\section{CAPÍTULO XXXI}

De los sabrosos razonamientos que pasaron entre don Quijote y Sancho Panza, su escudeiro, com otros sucesos (Cervantes, 2004, p. 310).

Essa característica do texto escrito não é retomada na encenação da obra, que é apresentada do início ao fim sem interrupções e sem menção a cada um dos subtítulos que a compõem. ${ }^{3}$ Desse modo, o texto habita uma espécie de fronteira entre o romance e o teatro, preservando características compartilháveis entre os dois gêneros e, ao mesmo tempo, outras características não compartilháveis, uma vez que só são viáveis dentro de cada uma das diferentes linguagens artísticas. Tomamos como outro exemplo as várias descrições das ações e sensações que devem ser exprimidas pelo ator, em cena, que são anunciadas pelo narrador; contudo, a realização concreta dessas ações só pode ser contemplada na encenação, sendo recuperável apenas parcialmente pelo texto escrito.

Essa fronteira entre teatro e romance, intencionalmente explorada pelo escritor, é representativa do drama pessoal elaborado no texto que, novamente, remete ao limite cada vez mais opaco entre vida e obra, autor e personagem. Uma imagem que condensa a representação de um limiar diz respeito à pele, que é também a matéria por meio da qual se vivencia a experiência irredutível da doença: "HOMEM: A coisa mais triste do mundo é a pele. Fronteira, limite que nos separa dos outros e das coisas. A pele é instransponível como uma muralha. (Olhando as mãos.) E tem

\footnotetext{
${ }^{3}$ A primeira montagem da peça "O homem e a mancha" estreou em 21 de novembro de 1996, no Theatro São Pedro, em Porto Alegre (RS), nove meses após o falecimento de Caio Fernando Abreu.
} 
manchas tristes, tristes, tristes" (Abreu, 2009, p. 253). A imagem da pele comporta uma ambivalência, pois, ao mesmo tempo que se constitui de uma matéria comum a todos os corpos, ela é também a delimitação de um corpo e de um único ser; matéria que traduz em experiência sensível o prazer e o sofrimento. A imagem da pele, sobretudo a pele adoecida, é representativa da experiência da solidão que, no fim de sua vida, era indissociável da vivência pessoal do próprio escritor, recluso e convalescente na casa de seus pais, em Porto Alegre.

Ao retomarmos o texto de Caio Fernando Abreu, publicado no início da década de 1980, diante do anúncio dos primeiros casos e aids, e compará-lo com a peça de teatro, escrita meses antes da confirmação de sua soropositividade e diante da perspectiva do fim da própria vida, observamos uma diferença significativa. No primeiro texto, o narrador recua diante da possibilidade de abordar de modo aberto e doloroso as consequências da aids. Àquela altura, soaria como uma crueldade imputar a seus próprios personagens um desfecho tão sofrido. Já em textos do fim de sua vida, como no caso de "O homem e a mancha", Caio Fernando Abreu não se esquiva de falar sobre a doença - nesse caso, sem metáforas - e sobre o mal, seja o "mal" a materialização de um "outro" temível socialmente, seja também o preconceito instituído contra a doença e contra grupos sociais. Dentro de seus próprios limites, Caio Fernando Abreu procura ir às últimas consequências na exposição do ponto de vista de quem é acometido por uma doença grave, cujo sofrimento é amplificado diante do estigma e da exclusão social. Há uma intenção declarada do autor de questionar o preconceito em relação à aids a partir da exposição de sua própria experiência. Já que o outro temível, a aids, se tornou o si mesmo para o escritor, não lhe resta saída a não ser assumir esse outro como um traço constitutivo de sua experiência e não se esquivar de falar sobre ele, que é, ainda, falar sobre si.

\section{Referências}

ABREU, Caio Fernando (2006). Pequenas epifanias. Rio de Janeiro: Agir.

ABREU, Caio Fernando (1983/2007). Pela noite. In: ABREU, Caio Fernando. Triângulo das águas. Porto alegre: L\&PM. p. 103-226.

ABREU, Caio Fernando (2009). O homem e a mancha. In: ABREU, Caio Fernando. Teatro completo. Rio de Janeiro: Agir. p. 217-258. 
ABREU, Caio Fernando (2010). Os dragões não conhecem o paraíso. Rio de Janeiro: Nova Fronteira.

ARENAS, Fernando (1999). Writing after paradise and before a possible dream: Brazil's Caio Fernando Abreu. Luso-Brazilian Review, Madison, v. 36, n. 2, p. 1321, Winter.

BUITONI, Dulcilia Schroeder (1997). Aids: falas e silêncios em revistas masculinas e femininas. Revista USP, São Paulo, n. 33, Dossiê Aids, p. 149-157.

CERVANTES, Miguel de (2004). Don Quijote de la Mancha. Madrid: Real Academia Española; Santillana del Mar: Santillana Ediciones Generales. v. 1 e 2.

GIOVANNETTI, Andrea; ÉVORA, Iolanda (1997). A aids como construção social. Revista USP, São Paulo, n. 33, Dossiê Aids, p. 127-135.

NOLL, João Gilberto (2017). Escrever é um ato radical de liberdade. Entrevista Gisela Anauate Bergonzoni. Peixe-elétrico, São Paulo, 31 mar. Disponível em: <https://goo.gl/1v9Y2d>. Acesso em: 24 abr. 2017.

SONTAG, Susan (2007). Doença como metáfora, AIDS e suas metáforas. São Paulo: Companhia das Letras.

Recebido em 22 de maio de 2017.

Aprovado em 7 de janeiro de 2018.

\section{resumo/abstract/resumen}

\section{Esse vírus de science fiction: doença e alteridade em Caio Fernando Abreu}

Milena Mulatti Magri

Neste trabalho, procuramos analisar diferentes formas de apresentação da aids na obra de Caio Fernando Abreu, tendo em vista, sobretudo, dois momentos distintos. $\mathrm{O}$ primeiro momento diz respeito à divulgação dos primeiros casos de aids no Brasil, e o segundo, ao momento posterior à confirmação para o próprio autor do diagnóstico da doença. A aids é caracterizada, desde seu surgimento, como uma doença socialmente temida e estigmatizada, o que acabou promovendo formas de exclusão social de pacientes soropositivos. A comparação destes diferentes momentos permite observar uma mudança na forma de compreensão da aids na obra de Abreu, que passa de um evento alheio e temível a uma alteridade que passa a ser constitutiva do próprio sujeito.

Palavras-chave: alteridade, aids, Caio Fernando Abreu. 


\section{This virus of science fiction: disease and otherness in the work of Caio Fernando Abreu}

\section{Milena Mulatti Magri}

In this essay, we analyse how Caio Fernando Abreu's work represents AIDS during two distinct moments. The first moment is concerned with the appearance of the first cases of AIDS in Brazil. The second moment is concerned with the writer's diagnosis of the disease. AIDS is characterized, since its beginning, as a socially feared and stigmatized disease, which engendered the social exclusion of seropositive patients. The comparison of these two different moments allows us to observe a change in how Abreu's work understands the disease. The texts shift from a perception of the disease as strange and fearsome to a form of otherness that becomes an integral part of the self-subject.

Keywords: otherness, AIDS, Caio Fernando Abreu.

\section{Este virus de science fiction: enfermedad y alteridad en Caio Fernando Abreu}

\section{Milena Mulatti Magri}

En este trabajo, procuramos analizar las diferentes formas de presentación del sida en la obra de Caio Fernando Abreu, mirando especialmente dos momentos diferentes. El primer momento está relacionado con la divulgación de los primeros casos de sida en Brasil, y el segundo está relacionado con la confirmación al escritor de su proprio diagnóstico de la enfermedad. El sida se caracteriza, desde su aparición, como una enfermedad temida socialmente y estigmatizada, lo que causó formas de exclusión social de pacientes con VIH. La comparación de estos diferentes momentos permite observar un cambio en la forma de comprensión del sida, en la obra de Abreu, que pasa de un evento ajeno y temible a una especie de alteridad constitutiva del proprio sujeto.

Palabras clave: alteridad, sida, Caio Fernando Abreu.

\section{Nota:}

A autora é bolsista da Fundação de Amparo à Pesquisa do Estado de São Paulo (Fapesp). 